\title{
EDUCAÇÃO EM SAÚDE PARA AGENTES COMUNITÁRIOS DE SAÚDE ${ }^{1}$
}

\section{Education in health for health community agents Educación en salud para agentes comunitarios de salud}

\author{
Carmem Lúcia Colomé Beck² \\ Maria Saleti Vogt ${ }^{3}$ \\ Pedro Luis Da Silva Galvão ${ }^{4}$ \\ Rosa Ladi Lisbôa ${ }^{4}$ \\ Juliana Petri Tavares ${ }^{5}$ \\ Denise Quatrin Lopes ${ }^{6}$
}

\begin{abstract}
RESUMO
Relato de experiência de um programa de extensão intitulado Programa Saúde do Trabalhador na perspectiva da educação em saúde, realizado junto a 11 Agentes Comunitários de Saúde (ACS), de uma unidade de saúde, do município de Santa Maria, localizado no estado do Rio Grande do Sul. O objetivo foi realizar a educação em saúde desses trabalhadores, oportunizando o trabalho coletivo entre acadêmicos de Enfermagem e de Fisioterapia. Foram realizados encontros na unidade de saúde, com temas selecionados a partir das necessidades elencadas pelas ACS. Esse trabalho propiciou a troca de saberes entre todos os sujeitos que participaram do processo e contribuiu para a melhoria da saúde física e mental das agentes, as quais são imprescindíveis à qualidade de vida das mesmas, bem como para o trabalho realizado por elas junto a essas comunidades.

Palavras-chave: saúde do trabalhador; educação em saúde; Enfermagem; Fisioterapia.
\end{abstract}

\begin{abstract}
A report of the experience of an extent program entitled "Occupational Health Program in the perspective of health education", held with 11 Community Health Agents (CHA) from a health unit of Santa Maria municipality, located in the state of Rio Grande do Sul. The objective was to carry out the health education of those employees, providing opportunities to the collective work between Nursing and Physiotherapy academics. Meetings were held in the health unit, with topics selected from the requirements listed by the $\mathrm{CHA}$. This work provided the exchange of knowledge among all subjects who participated in the process and contributed to the improvement of physical and mental health of the agents, which are essential to their quality of life, and for the work done by them with those communities.
\end{abstract}

Keywords: Occupational health; Education in health; Nursing; Physiotherapy.

\footnotetext{
1 Artigo original do relato de experiência do Programa Saúde do Trabalhador na perspectiva da educação em saúde. Apoio financeiro do Fundo de Incentivo à Extensão (FIEX/UFSM).

2 Enfermeira, Professora Associada do Departamento de Enfermagem da Universidade Federal de Santa Maria/UFSM. Membro do Grupo de Pesquisa Trabalho, Saúde, Educação e Enfermagem/UFSM. Doutora em Enfermagem/UFSC. Coordenadora do Programa de Extensão.

3 Fisioterapeuta, Professora Adjunta do Departamento de Fisioterapia e Reabilitação da Universidade Federal de Santa Maria/UFSM. Doutora em Fisioterapia/UnB.

4 Acadêmico de Fisioterapia da Universidade Federal de Santa Maria. Bolsista do Fundo de Incentivo à Extensão (FIEX/ UFSM) deste projeto.

5 Acadêmica de Enfermagem da Universidade Federal de Santa Maria/UFSM. Membro do Grupo de Pesquisa Trabalho, Saúde, Educação e Enfermagem/UFSM. Bolsista do Fundo de Incentivo à Extensão (FIEX/ UFSM) deste projeto.

6 Enfermeira, Mestranda em Enfermagem pelo Programa de Pós-Graduação em Enfermagem da UFSM. Membro do Grupo de Pesquisa Trabalho, Saúde, Educação e Enfermagem/UFSM.
} 


\section{RESUMEN}

Relato de experiencia de un programa de extensión intitulado "Programa Salud del Trabajador en la perspectiva de la educación en salud", realizado junto a 11 Agentes Comunitarios de Salud (ACS) de una unidad de salud del municipio de Santa Maria, localizado en la provincia del Rio Grande do Sul. El objetivo fue realizar la educación en salud de esos trabajadores, permitiendo el trabajo colectivo entre académicos de Enfermería y de Fisioterapia. Fueron realizados encuentros en la unidad de salud, con temas seleccionados a partir de las necesidades designadas por las ACS. Ese trabajo propició el cambio de conocimientos entre todos los sujetos que participaron del proceso y contribuyó para la mejoría de la salud física y mental de las agentes, las cuales son imprescindibles a la cualidad de vida de las mismas, bien como para el trabajo realizado por ellas junto a estas comunidades.

Palabras-clave: Salud del trabajador; Educación en salud; Enfermería; Fisioterapia.

\section{Introdução}

A criação do Sistema Único de Saúde na Constituição de 1988 e sua implantação, a partir das Leis 8.080/90 e 8.142/90, determinaram a reestruturação do modelo de saúde no Brasil. Assim, o Ministério da Saúde (MS) estruturou os Programas de Saúde da Família (PSF) e o Programa dos Agentes Comunitários de Saúde (PACS) como estratégias para operacionalizar estas mudanças (BRASIL, 2003).

A profissão de Agente Comunitário de Saúde foi criada pela Lei n. ${ }^{\circ} 10.507$, de 10 de julho de 2002 e seu exercício dar-se-á exclusivamente no âmbito do Sistema Único de Saúde e sob a supervisão do gestor local. Assim, o Agente Comunitário de Saúde passa a integrar as equipes do PACS e PSF, devendo realizar atividades de prevenção de doenças e promoção da saúde, por meio de ações educativas nos domicílios e coletividade, em conformidade com as diretrizes do SUS, estendendo o acesso às ações e serviços de informação, promoção social e de proteção da cidadania.

A Portaria do Ministério da Saúde n. ${ }^{\circ}$ 1.886, de 18 de dezembro de 1997, estabelece as atribuições do ACS e o Decreto Federal n. 3.189 , de 04 de outubro de 1999, fixa diretrizes para o exercício de suas atividades, possibilita uma proposição qualitativa de suas ações, evidenciando-se um perfil profissional que prevê também a mobilização de recursos e práticas sociais de promoção da vida $e$ cidadania e orientação de indivíduos, grupos e populações com características de educação popular em saúde, acompanhamento de famílias e apoio socioeducativo. Desta forma, o Agente Comunitário de Saúde torna-se o principal elo entre os serviços de saúde e a comunidade e, assim sendo, deve residir na microárea de abrangência do seu trabalho, o que pode apontar para um envolvimento diferenciado com os problemas que comprometem a saúde das famílias que ele acompanha.

As características da organização do trabalho desenvolvido pelos ACS trazem repercussões tanto na esfera física, quanto na afetiva, ou seja, nos sentimentos destes trabalhadores, os quais podem ser prazerosos e fortalecedores da identidade e da saúde, mas também potencialmente desgastantes, gerando estresse físico e mental.

Segundo Trindade, Gonzales, Beck e Lautert (2007), estudos epidemiológicos recentes apontam epidemias das chamadas doenças profissionais ou doenças relacionadas ao trabalho. Estudos específicos sobre sofrimento e prazer no trabalho também mostram uma evolução quantitativa e qualitativa dos fatores de risco à saúde do trabalhador dentro das diversas categorias profissionais (DEJOURS, 1992; DEJOURS, C.; ABDOUCHELI, E.; JAYET, C, 1994; FRANÇA, A. C. L.; RODRIGUES, A. L, 1997; SELIGMANN-SILVA, 1994; MENDES et al., 2007).

Os cuidados destinados a essas populações, pela sua complexidade, podem 
implicar em sobrecarga emocional dos trabalhadores e adoecimento dos mesmos. Trindade, Gonzales, Beck e Lautert (2008) referem que o cuidado à Saúde dos Trabalhadores decorre do crescente adoecimento desta parcela populacional que, por vezes, esquece de cuidar da própria saúde e das condições de seu ambiente de trabalho. Particularmente no caso dos ACS, eles necessitam desenvolver habilidades específicas para o cuidado a estas comunidades, bem como se preocuparem com um ambiente de trabalho favorável às suas atividades. Quando os agentes comunitários não atentam para estas questões, têm o seu risco de adoecimento aumentado.

Nesse contexto, ressalta-se a importância do trabalhador em saúde, tendo em vista ser instrumento de construção dos caminhos desse "novo jeito de olhar e de fazer saúde".

A incorporação de novos conceitos pelos profissionais da área a respeito da compreensão ampliada do processo saúdedoença, a humanização das práticas, a busca da qualidade da assistência e de sua resolutividade, possibilitam o investimento no modelo dialógico de educação em saúde, acreditando-se ser este um modelo pertinente para a efetivação de mudanças, incentivando a autonomia de escolha dos sujeitos, reconhecendo-os como portadores de um saber que, embora diverso do saber técnico-científico, não deve ser deslegitimado pelos serviços (TOLEDO; RODRIGUES; CHIESA, 2007).

Ser um educador em saúde constituiuse em um importante e necessário instrumento do cuidado dos trabalhadores da saúde (TAUBE; SILVA, 2004). Entretanto, ainda se identifica nas práticas de saúde a utilização de uma concepção estática de educação, entendida apenas como transferência de conhecimento, em que o trabalhador "deposita" seus conhecimentos científicos nos usuários, denominada de educação bancária (FREIRE, 1985). Desta forma, os agentes comunitários comumente não conseguem aplicar as orientações recebidas através da utilização desta metodologia no seu cotidiano e deixam de realizar o autocuidado ou ações de saúde devidamente.

Pretende-se, como docentes vinculados à saúde, contribuir para a formação $e$ desenvolvimento da consciência crítica dos ACS a respeito de seus problemas de saúde (BOVA; WALL, 2005), sendo imprescindível que esta prática esteja vinculada e pautada em uma proposta educacional de transformação social.

\section{Metodologia}

Nesse programa, escolheu-se como estratégia de intervenção na educação em saúde a construção compartilhada do conhecimento entre profissionais e acadêmicos da área da saúde e os agentes comunitários. Na execução dessa proposta, pretendeu-se que os ACS se tornassem sujeitos ativos do processo de autocuidado, assumindo o papel de multiplicadores das orientações, junto à sua comunidade.

Diante dessas questões, foi implementado um programa de extensão junto a um grupo de agentes comunitários, com o objetivo de realizar a educação em saúde para os mesmos.

Foram envolvidos nesse programa agentes de uma unidade de saúde do município de Santa Maria/RS, bem como dois acadêmicos e dois professores do curso de Enfermagem e de Fisioterapia da Universidade Federal de Santa Maria (UFSM), na perspectiva do trabalho coletivo e interdisciplinar.

O Programa Saúde do Trabalhador foi idealizado a partir de necessidades identificadas por uma enfermeira coordenadora do PACS do município, as quais foram ressaltadas após diagnóstico junto aos ACS. Assim, foi construída coletivamente, por professores e acadêmicos dos cursos de enfermagem e de fisioterapia, 
a proposta de intervenção, sendo o programa registrado junto ao Sistema de Registro de Informações (SIE) da instituição e tramitado para a chefia do departamento. Posteriormente foi encaminhado, via sistema, para a Comissão de Ensino, Pesquisa e Extensão do Centro de Ciências da Saúde (CCS), o qual foi aprovado e recebeu financiamento de duas bolsas para dois acadêmicos (um de enfermagem e um de fisioterapia) do Fundo de Incentivo à Extensão (FIEX) da Universidade Federal de Santa Maria (UFSM).

Após os trâmites institucionais, foram feitos os pactos de implantação do mesmo, junto à Secretaria de Saúde do Município, em combinação com a enfermeira do PACS e da unidade básica de saúde.

O programa foi desenvolvido no período de agosto a dezembro de 2008, totalizando dez encontros com as ACS, com realização quinzenal, utilizando-se a unidade de referência das agentes. $\mathrm{O}$ dia e a hora dos encontros foram estabelecidos de acordo com as possibilidades das agentes.

Para melhor contemplar as áreas da saúde, Enfermagem e Fisioterapia, a organização dos encontros ocorreu de forma integrada, sendo que cada um foi desenvolvido em conjunto com as duas áreas.

Os encontros contavam com a participação das Agentes Comunitários de Saúde, da enfermeira da unidade e da coordenadora do PACS, das professoras responsáveis pelo projeto, sendo uma da Enfermagem e a outra da Fisioterapia, de acadêmicos bolsistas do projeto de ambos os cursos já supracitados. Destaca-se que, em alguns encontros, também participaram acadêmicos do terceiro semestre do curso de enfermagem da UFSM, os quais realizavam aulas práticas naquela unidade de saúde.

A cada reunião era realizada uma dinâmica de grupo que objetivava favorecer a aproximação dos ACS entre si, bem como entre os demais participantes do programa.
A seguir serão apresentados os temas discutidos nos encontros, bem como as reflexões do referido grupo.

Apresentação e reflexão acerca dos temas desenvolvidos no grupo

Salienta-se que todas as agentes de saúde são do sexo feminino, o que pode evidenciar a questão de gênero a ser cuidadosamente considerada ao ser desenvolvido neste trabalho, o que justifica a utilização no texto do gênero feminino.

O primeiro encontro constituiu-se da apresentação dos membros do programa de extensão e dos agentes comunitários de saúde. Foram feitos esclarecimentos acerca da proposta de trabalho a ser desenvolvida, destacando-se a importância desse espaço protegido para o compartilhamento de ideias e o sigilo acerca das discussões ali efetivadas.

No primeiro tema trabalhado, cuidados com a própria saúde, foram realizadas orientações de saúde na vida diária, sendo elas: postura, alimentação, hidratação, consultas com médicos e dentistas e o uso do tabaco.

Os cuidados com a postura foram abordados tanto na execução das atividades laborativas, quanto no momento de repouso e descanso das ACS. As orientações foram realizadas em decorrência do relato de dores na região cervical e ombros no cotidiano do trabalho. Dentre algumas das possíveis causas dessas dores incluem-se o esforço físico nas caminhadas diárias durante realização das visitas domiciliares; o estresse da rotina diária que pode provocar tensão nervosa; o peso da balança de pesagem das crianças quando essa atividade é realizada.

Algumas agentes ao serem perguntadas sobre a postura adotada durante o sono e repouso noturno, relataram posturas inadequadas, as quais podem contribuir para o desenvolvimento deste processo. Nesse sentido, foram orientadas sobre algumas posições recomendadas para dormir, repousar, levantar, sentar, agachar, 
postura para as caminhadas diárias e também a realização de alongamentos antes, durante e após qualquer atividade que demande esforço físico.

As informações levantadas a partir desse trabalho vêm corroborar com afirmações de Trindade, Gonzales, Beck e Lautert (2008), para as quais as pressões ligadas às condições de trabalho têm por alvo principal o corpo do trabalhador e podem ocasionar desgastes $e$ doenças somáticas. Entretanto, além do desgaste físico, acarretam o sofrimento psíquico, pois todo indivíduo é portador de desejos e projetos.

O desgaste físico e mental faz parte do cotidiano dessas profissionais. As queixas de dor nas costas, nos pés e nas pernas são prevalentes, acrescendo a dor nos ombros $e$ nos braços, em virtude de carregarem durante o trabalho uma bolsa com objetos pessoais $e$ materiais de registro.

É possível que as dores físicas relatadas pelas ACS ocorram pela adoção de uma postura viciosa e inadequada, com descarga de peso unilateral no uso da bolsa durante todo o dia. Fica evidenciado, também, que nem sempre as ACS estão utilizando calçados adequados para as caminhadas diárias, pois preferem usar chinelos ou sapatos ao invés de um tênis confortável. Foi orientada a utilização de calçado confortável, de salto baixo (não maior que cinco centímetros) e, principalmente, a prática diária de alongamentos antes e após as atividades laborais, bem como o incentivo da atividade física algumas vezes na semana, fora do horário de trabalho.

Desse modo, foi fornecida orientação quanto aos cuidados posturais a serem adotados, de modo a minimizar ou mesmo extinguir essas dores, assim como quanto ao uso de roupas leves e flexíveis que não prejudiquem e causem desconforto na execução de tarefas.

A etiologia dos transtornos músculoesqueléticos em trabalhadores é multifatorial e vários fatores têm sido discutidos na literatura, tanto decorrentes de causas físicas, quanto de causas psíquicas, somadas às condições psicossociais e individuais (VOGT, 2000). Isso ficou evidente ao longo dos encontros, quando foi relatado pelas ACS, além da carga física diária, a cansativa cobrança por parte da comunidade de demandas que não dependem delas equacionarem - como um maior número de visitas, a falta de medicamentos e consultas em número suficiente, melhorias na qualidade dos serviços no bairro (saneamento básico, água e esgoto, má conservação das ruas), dentre outros.

Quanto à alimentação com frutas, legumes e verduras, com orientação para evitarem doces e gorduras, foi bastante discutida por parte de todas as trabalhadoras, as quais relataram não terem cuidado com a seleção dos alimentos que ingerem em cada refeição.

A alimentação inadequada, segundo elas, deve-se ao fato de a rotina de trabalho não propiciar tempo para o preparo de uma alimentação balanceada; dificuldade para se alimentar durante o horário de trabalho; cansaço durante o dia; pouco tempo para intervalo de almoço, visto terem de voltar rápido à unidade ou às visitas domiciliares.

A ingestão de líquidos durante as atividades de trabalho foi relatada como habitual entre as trabalhadoras, sendo que a maioria possui uma garrafa de água junto aos seus pertences pessoais. Ratificou-se a importância da hidratação durante o trabalho, principalmente nas atividades que implicam em deslocamento, como nas visitas domiciliares. O aumento da ingestão de líquidos nos meses de verão é referido pelas ACS e reforçado como positivo para a sua saúde.

Foi discutido no grupo com as ACS o cuidado que devem ter com a própria saúde, ou seja, privilegiar aspectos como as visitas regulares a um médico e ao dentista para consultas $e$ exames periódicos; a realização de atividades físicas regularmente e a prevenção do uso do tabaco como meio de prevenção de doenças. 
As ACS se queixaram da falta de tempo e de recursos financeiros para procurarem o atendimento de saúde. Relataram não realizar atividades físicas regularmente como caminhadas, corridas, uso da bicicleta, a frequência à academia, entre outras. Disseram possuir conhecimento da importância de exercícios para a prevenção de doenças crônicas, como a hipertensão e o diabetes, mas que o cansaço do dia a dia do trabalho, somado à demanda de serviços domésticos e da família, as extenuam, restando pouco tempo e energia para o cuidado de si.

Ainda em relação aos cuidados com a saúde, foi salientado que o hábito de fumar é prejudicial e pode acarretar no desenvolvimento e agravamento de diversas doenças. Neste grupo de trabalhadoras, algumas utilizam o tabaco $e$ pôde-se perceber que durante alguns encontros, estas não toleraram esperar até o final do encontro e saíam para fumar fora da sala.

Outro tema trabalhado com as ACS foi autoestima e autoimagem das trabalhadoras, no qual foi realizada uma dinâmica de conhecimento grupal, no intuito das ACS se conhecerem e/ou reconhecerem. Assim, na técnica, as ACS eram estimuladas a comentar com as colegas algumas características pessoais positivas das demais, o que também contribuiu para fortalecer o relacionamento entre elas e para a reflexão acerca da autoimagem, uma vez que a imagem refletida das demais trabalhadoras, nem sempre coincide com a visão que esta tem de si.

Estas questões também oportunizaram discussões acerca da importância da autoestima elevada para um exercício laboral efetivo. As ACS relataram as dificuldades relativas, por exemplo, ao trabalho com mulheres vítimas de violência, situação em que este aspecto é essencial. Evidenciaram a complexidade de contribuir com a melhoria da autoestima dos comunitários quando este quesito está prejudicado.

A identidade profissional dos ACS também foi bastante discutida nesse momento de reflexão, pois a falta de uma delimitação das atribuições, muitas vezes, faz com que o seu papel seja distorcido, sobrecarregando essa trabalhadora. Assim, qualquer ação que deva ser desenvolvida na comunidade é atribuída aos ACS (TOMAZ, 2002).

$$
\text { Comentou-se, além disso, o }
$$

desgaste do trabalho em equipe, porque são grupos heterogêneos, e segundo elas, há pessoas autoritárias, inquietas, com pouca paciência, rígidas quanto à maneira de pensar, ansiosas, nervosas e isso dificulta as relações interpessoais.

De acordo com Peduzzi (2001), o trabalho em equipe é construído, efetivamente, na relação intrínseca entre trabalho e interação: quanto mais próximo o estatuto de sujeito éticosocial dos agentes, maiores as possibilidades deles interagirem em situações livres de coação e de submissão, na busca de consensos acerca da finalidade e do modo de executar o trabalho. A autora reforça ainda que há possibilidade de construção da equipe-integração mesmo nas situações nas quais se mantêm relações assimétricas entre os distintos profissionais.

Um terceiro tema trabalhado com as ACS foi a importância do trabalho na suas vidas. Assim, foi sugerido que formassem duplas em que deveriam debater esse tema, bem como descrever como percebiam o seu trabalho, do ponto de vista da equipe de saúde e da comunidade. De uma maneira geral, as trabalhadoras relataram trabalharem felizes, com senso de humor, ajuda mútua, determinação, vontade de aprender. Ressaltam a satisfação por trabalharem na região onde residem, tendo em vista conhecerem a população, criarem vínculo, amizade e aproximação, o que facilita o trabalho. Outra característica comentada e de muita importância para as ACS é a espiritualidade, como ferramenta que as ajuda a vencer as dificuldades e percalços do trabalho.

As ACS reconhecem o seu trabalho como muito importante, pois se sentem 
responsáveis por muitas ações, como pesagem de crianças para avaliação de seu desenvolvimento, visitas regulares aos domicílios, marcação de consultas e visitas dos demais membros da equipe de saúde, dentre outras inúmeras atividades.

Sentem-se "representantes da vila" junto à unidade de saúde, referência para esclarecimento de qualquer dúvida em relação à saúde das pessoas. Percebem que têm reconhecimento do seu trabalho por parte da comunidade, pois exercem seus direitos e cumprem com esmero e dedicação seus deveres.

Apesar das ACS sentirem-se valorizadas pelas demais colegas de trabalho $e$ pela comunidade em que atuam, muitas vezes tais trabalhadoras evidenciaram sentirem-se desvalorizadas e desmotivadas com relação ao atraso no pagamento do salário.

Além disso, salientaram que é preciso, no contato com a comunidade, ater-se principalmente aos assuntos referentes à saúde $e$ necessidades das famílias, evitando interferência nos problemas pessoais das mesmas. Assim, é fundamental manter o sigilo profissional, não comentando com outras famílias questões particulares de outras, o que, segundo as ACS, desperta muito interesse e curiosidade da comunidade, além do desgaste psíquico em saber dos problemas particulares das famílias.

Nessa direção, Fortes e Spinetti (2004) afirmam que o direito do usuário à privacidade deriva do dever da manutenção do segredo por todos os elementos da equipe: profissionais, técnicos, auxiliares, corpo administrativo e ACS, constituindo-se em uma obrigação ética.

$\mathrm{O}$ outro tema dialogado com as ACS foram as facilidades e dificuldades encontradas no exercício profissional. Neste aspecto, elas destacaram como facilidades: conhecer $e$ residir na comunidade, uma das diretrizes do PACS; maior tempo residindo na comunidade, o que facilita o vínculo e a aproximação com os comunitários; a confiança dos usuários que recebem as ACS nos seus domicílios; gostar do que fazem e os laços de amizade construídos entre as agentes, a equipe de saúde e a comunidade em que atuam. Essa facilidade, de acordo com Nunes et al. (2002), decorrente dos ACS serem pessoas atuantes na comunidade, pode gerar de forma direta ou indireta conflito de poder, que se instaura quando esses trabalhadores passam a disputar ou dividir o prestígio na comunidade com outros trabalhadores.

A respeito das dificuldades, é citado que o horário de trabalho não é respeitado, pois em dias frios as pessoas acordam mais tarde e só aceitam visitas no final da manhã, exigindo, assim, horas extras de trabalho para que as mesmas sejam realizadas. A existência de cachorros soltos no pátio muitas vezes também dificulta ou até impossibilita a entrada das ACS nas residências; além das adversidades climáticas, como o frio e a chuva, pois as ACS trabalham molhadas mesmo com proteção do guarda-chuva.

Outro aspecto relatado pelas agentes, que interfere negativamente no seu exercício laboral, é a falta de higiene em alguns domicílios, bem como a presença de inúmeros animais domésticos. Também evidenciam a dificuldade para visitar os comunitários que trabalham durante o dia; bem como a adesão da comunidade aos grupos e atividades da unidade de saúde, como o grupo de hipertensos e diabéticos. A falta de medicação na unidade de saúde também é motivo de cobrança das famílias, o que gera preocupação para as ACS, pois os comunitários encaminham as solicitações à defensoria pública, o que resulta em cobrança das pessoas que estão precisando da medicação e não compreendem que esse é um processo complexo e demorado.

ComoogrupodasACSéessencialmente feminino, existe ainda o envolvimento com o ambiente doméstico, a dupla jornada de trabalho, a presença de filhos e esposo para 
atender. Além de outras atribuições, destaca-se o preparo da alimentação, a higiene do lar, o cuidado com as roupas, cuidado com os filhos, o acompanhamento do andamento escolar das crianças e a atenção à família. Essas ações, segundo elas, implicam em exigências, disciplina, coragem, responsabilidade, autocobrança elevada, impaciência, nervosismo, ansiedade e resultam em sobrecarga física e mental, sendo também fatores que dificultam o exercício profissional dos ACS.

\section{Considerações finais}

Na execução da proposta, pretendeuse que as ACS se tornassem sujeitos ativos do processo de autocuidado, assumindo o papel de multiplicadoras das orientações junto à sua comunidade, o que, na fala das ACS, pareceu se efetivar de maneira significativa. Ressaltaram sentirem-se mais preparadas para orientarem novas posturas e comportamentos, especialmente, frente aos aspectos trabalhados no grupo.

Todos os encontros com as agentes comunitárias de saúde propiciaram perceber,

\section{REFERÊNCIAS}

BOVA, V. B. R; WALL M. L. Educação em saúde no trânsito: uma contribuição da Enfermagem. Cogitare Enferm., v. 10, n. 1, p. 60-5, 2005.

BRASIL. Ministério da Saúde. Lei $n^{\circ}$ 10.507/2002, que cria a profissão de Agente Comunitário de Saúde. [2003]. Disponível em: <http:/www.portal.saude.gov.br/portal/ sgtes/visualizar_texto.cfm?idtxt $=23176-19 \mathrm{k}>$. Acesso em: 17/4/2009.

DEJOURS, C. A loucura do trabalho: estudo de psicopatologia do trabalho. São Paulo: Atlas, 1992.

; ABDOUCHELI, E.; JAYET, C. Psicodinâmica do trabalho: contribuições da escola dejouriana à análise da relação prazer, sofrimento e trabalho. São Paulo: Atlas, 1994. sob a ótica delas, que o trabalho é gratificante e extenuante ao mesmo tempo.

O desenvolvimento desse programa de extensão possibilitou às agentes comunitárias de saúde o (re)conhecimento da vivência do exercício profissional e os reflexos no próprio trabalho e na vida pessoal, incluindo a saúde. Salienta-se a importância de haver um equilíbrio físico, psíquico e social das trabalhadoras como um todo, para que não ocorram desgastes desnecessários à saúde.

Comoum importanteresultado, pode-se destacar o trabalho interdisciplinar desenvolvido entre a Enfermagem e a Fisioterapia, de forma objetiva e enriquecedora para ambas as áreas; além de ter sido esta parceria muito valorizada pelas ACS.

Esse programa contribuiu muito para o conhecimento das condições de trabalho das ACS pela equipe de estudantes e docentes, bem como para o conhecimento das trabalhadoras de novos meios que proporcionem bem-estar durante o trabalho, que poderá resultar no autocuidado e proteção para com a sua saúde.

As avaliações dos encontros ocorreram de forma processual, valorizando-se as vivências de cada um dos participantes do programa, bem como a construção coletiva dos conhecimentos partilhados neste grupo.

FRANÇA, A. C. L.; RODRIGUES, A. L. Stress e trabalho - guia básico com abordagem psicossomática. São Paulo: Atlas, 1997.

FORTES, Paulo Antonio de Carvalho; SPINETTI, Simone Ribeiro. O agente comunitário de saúde e a privacidade das informações dos usuários. Cad. Saúde Pública [on-line], v. 20 , n. 5 , p. 1328-1333, 2004. Disponível em: <http: //www.scielo.br/scielo.php?script=sci_arttext\&pid=S0102311X2004000500027>. Acesso em: 16/9/2008.

FREIRE, P. Reflexão crítica sobre as virtudes da educadora ou do educador. Buenos Aires: [2003], 1985. Disponível em: <http://www.redepopsaude.com.br.html>. Acesso em: 10/8/2004. 
MENDES, A. M. et al. Psicodinâmica do trabalho: teoria, métodos e pesquisa. São Paulo: Casa do Psicólogo, 2007.

NUNES, M. O.; TRAD, L. B.; ALMEIDA, B. A.; HOMEME, C. R.; MELO, M. C. I. C. O agente comunitário de saúde: personagem híbrido e polifônico. Cad. Saúde Pública [on-line], v. 18, n. 6, p. 1639-1646, 2002. Disponível em: < http://www.busde.paho.org/bvsacd/cd26/fulltexts/ 0747.pdf> . Acesso em: 19/6/2008.

PEDUZZI, Marina. Equipe multiprofissional de saúde: conceito e tipologia. Rev. Saúde Pública [on-line], v. 35, n. 1, 2001. Disponível em: <http://www.scielosp.org/ scielo.php?script $=$ sci_arttext\&pid $=$ S0034-89102001000 100016 > . Acesso em: 22/6/2008.

SELIGMANN-SILVA, E. Desgaste mental no trabalho dominado. Rio de Janeiro: Cortez/UFRJ, 1994.

TAUBE, S.; SILVA, M. C. E. P. A educação em saúde para portadores de doença crônica oftálmica: um relato de experiência. Cogitare Enferm., v. 9, n. 2, p. 66-72, 2002.
TOLEDO, M. M.; RODRIGUES, S. C.; CHIESA, A. M. Educação em saúde no enfrentamento da hipertensão arterial: uma nova ótica para um velho problema. Texto contexto - Enferm., Florianópolis, v. 16, n. 2 , abr.jun. 2007. Disponível em: <http://www.scielosp.org/ scielo.php?script $=$ sci_arttext\&pid $=$ S0104-07072007000 200004\&Ing=pt\&nrm=iso $>$. Acesso em: 06/8/2008.

TOMAZ, J. B. C. O Agente Comunitário de Saúde não deve ser um "super-herói". Interface-Comunic. Saúde, Educ., v. 6, n. 10, p. 75-94, fev. 2002. Disponível em: <http: //www.fm.usp.br/cedem/did/atencao/debates2.pdf > . Acesso em: 14/8/2008.

TRINDADE, L. L.; GONZALES, R. M. B.; BECK, C. L. C.; LAUTERT, L. Cargas de trabalho entre os agentes comunitários de saúde. Rev. Gaúcha de Enfermagem, Porto Alegre, v. 28, n. 4, p. 473-479, 2008.

VOGT, M.S. Prevalência e severidade da dor, cervical e lombar, nos servidores técnico-administrativos da Universidade Federal de Santa Maria-RS. Dissertação (Mestrado) - UFSC, Florianópolis, 2000.

Texto recebido em 26 de fevereiro de 2009. Texto aprovado em 17 de abril de 2009. 